\title{
POETRY
}

\section{I went to the cenotaph today}

I went to the cenotaph today. It wasn't the official ceremony, The one with the mayor and speeches, People in uniform, old and young: They'd moved that indoors. I was on call but I thought The least I could do Was to take a few moments, And reflect.

It stood there as always, Stone and copper, Dead leaves blowing around. Don't notice it most of the year. Slowly people began to gather: Quiet nods of greeting, murmurs Some in fancy clothes Some right off the street A couple of uniforms, a few kids. Almost everyone had a poppy, A few others had wreaths. One guy brought some old photos, Set them on the stone,

I walked around the monument. It was quiet, people in their own space. Collectively.

Nothing official going on:

Then the church started to chime eleven, Somewhere a big gun went off, And we stood.

Quietly.

Even the kids.

I whispered the Lord's Prayer, Seemed appropriate.

The gun sounded again, and Slowly, a scruffy looking guy About my age but not as fortunate, Shuffled up to the stone. Put his smoke in his mouth So he had two hands free, Took off his poppy, Stuck it on a wreath. Gradually, We all did it, Then quietly drifted away. I went to the cenotaph today: Think I'll go again next year.

\section{James Stephenson MD Department of Geriatrics St. Joseph's Hospital St. John, NB}

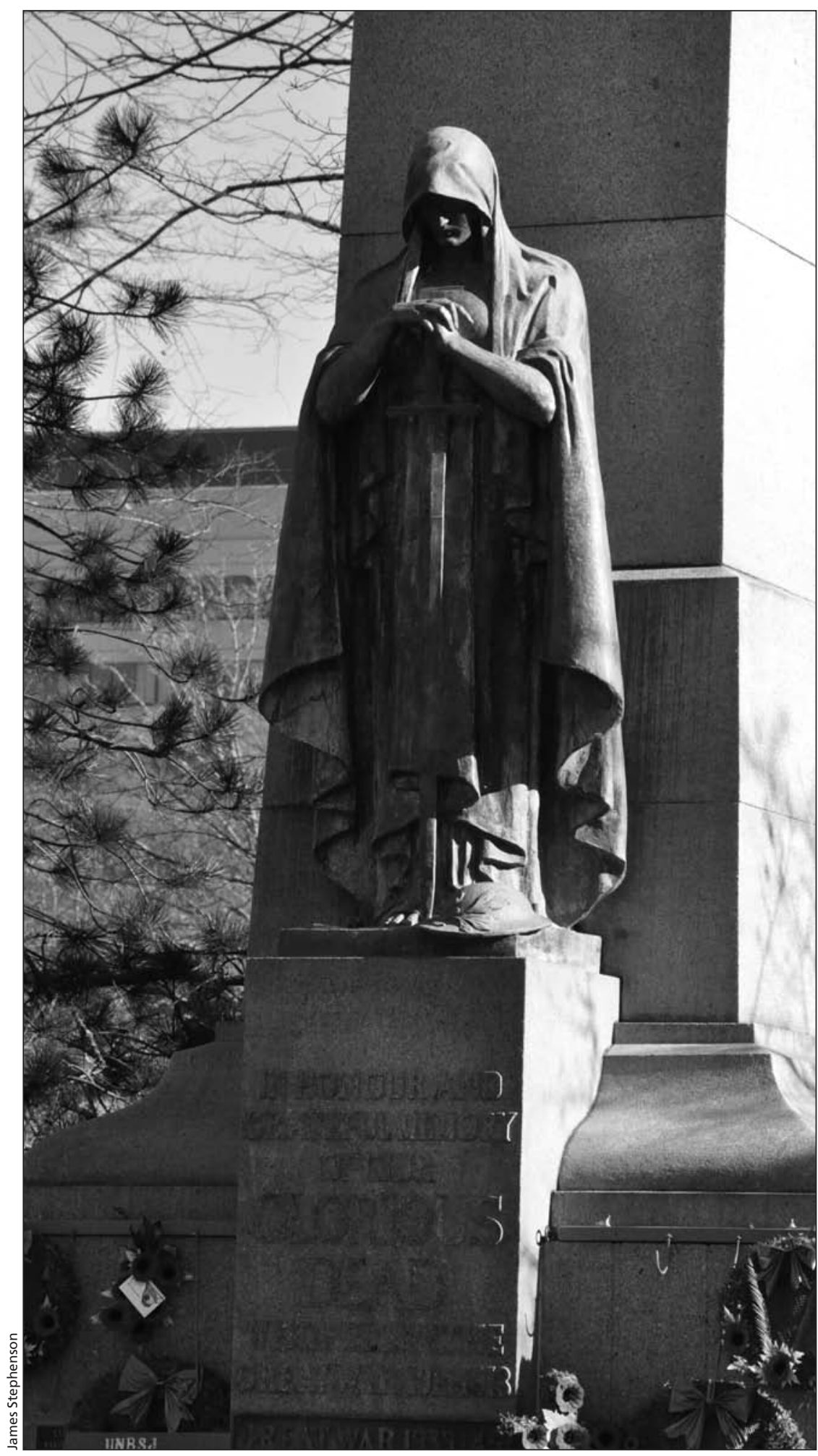

두 2012 Canadian Medical Association or its licensors 